\title{
Anthropometric data and the cross-sectional area (CSA) of the semitendinosus and gracilis tendons measured with preoperative MRI to predict graft diameter for anterior cruciate ligament reconstruction
}

\author{
M.S. Ryazantsev ${ }^{1}$, N.E. Magnitskaya ${ }^{1}$, A.R. Zaripov ${ }^{1,2}$, A.N. Logvinov ${ }^{1}$, D.O. Ilyin ${ }^{1}$, A.P. Afanasyev ${ }^{1}$, \\ A.V. Frolov ${ }^{1,2}$, A.V. Korolev ${ }^{1,2}$ \\ ${ }^{1}$ European Clinic of Sports Traumatology and Orthopaedics (ECSTO), Moscow, Russian Federation \\ ${ }^{2}$ Peoples' Friendship University of Russia, Moscow, Russian Federation
}

\begin{abstract}
Introduction Anterior cruciate ligament (ACL) reconstruction with quadrupled hamstring tendon autograft is a safe and reproducible surgery with good functional outcomes. Currently there is no consensus on capability of graft diameter planning. Objectives To investigate the influence of anthropometric data and cross-sectional area of semitendinosus (ST) and gracilis (GR) tendons according to preoperative magnetic resonance imaging (MRI) on intraoperative graft diameter. Material and methods The study included 111 consecutive patients (69 men and 42 women), who underwent ACL reconstruction with quadrupled hamstring autograft between 2015 to 2018. Height, weight and BMI were recorded in all patients preoperatively. Semitendinosus and gracilis tendons cross sectional areas (CSAst and CSAgr, respectively) were evaluated on preoperative MRI axial images. We also calculated doubled and quadrupled graft diameters (CSAst + gr and CSA4p, respectively) based on obtained MRI data. Collection of intraoperative data included length of each tendon separately, length and diameter of the resulting autograft. We used linear regression and Pearson correlation coefficient were used. The cross-sectional areas were correlated to antropometric and intraoperative data. Using logistic regression, we determined the probability of obtaining a graft diameter of $\geq 7.5 \mathrm{~mm}$. A critical level of statistical significance was set as $5 \%(\mathrm{p} \leq 0.05)$. Results The median age accounted $37.4 \pm 0.89(13-58)$ years, height $-174.6 \pm 0.84(156-200) \mathrm{cm}$, weight $-78.5 \pm 1.52(45-120) \mathrm{kg}, \mathrm{BMI}-25.6 \pm 0.37$ (18.49-41.5). Intraoperatively GR average length was $224.7 \pm 3.06(80-340) \mathrm{mm}, \mathrm{ST}-256.3 \pm 2.97$ (160-340) mm, quadrupled graft $-111.3 \pm 1.42(80-140) \mathrm{mm}$. The most common graft diameter was $7 \mathrm{~mm}$ in females and $7.5 \mathrm{~mm}$ in males. We found strong positive correlation between graft diameter and CSA4p, CSAst+gr, CSAst, weight and height. Linear regression showed that graft diameter was influenced by CSA4p, CSAst + gr, CSAst and height. If CSA4p was $\geq 72 \mathrm{~mm}^{2}$, the probability of obtaining a graft of $\geq 7.5 \mathrm{~mm}$ at the time of surgery reached $90.6 \%$. Conclusion CSA $4 \mathrm{p}$ may be used as a predictive characteristic for graft diameter preoperative planning. Our findings show that graft diameter was mainly influenced by height, CSAst+gr, CSAst and CSA4p.
\end{abstract}

Keywords: anthropometric data, anterior cruciate ligament reconstruction, graft diameter, planning

\section{INTRODUCTION}

Anterior cruciate ligament (ACL) injury is among the most commonly studied injuries in orthopaedics. With increasing number of ACL injuries, there are more surgical interventions offered for ACL reconstruction. PubMed library of medicine provided 1623 citations for the search "anterior cruciate ligament" in 2019 with 1372 published in 2017 and 1472 brought out in 2018. S. Abram et al. reported a 22-fold increase in the rate of ACL reconstruction for patients younger than 20 years, an 11.5-fold increase for patients aged 20-29 and an 8.6-fold increase for patients aged 30-39 between 1997 and 2017 [1]. An ACL reconstruction with a semitendinosus/gracilis autograft show good outcomes at a mean follow-up period of 14.6 years $[2,3]$. Recent studies have identified a relationship between the graft diameter and the likelihood of a failure. T. Snaebjörnsson et al. reported a 0.86 times lower likelihood of revision surgery with every $0.5-\mathrm{mm}$ increase in the graft diameter [4]. The diameter and the length of the quadrupled semitendinosus and gracilis tendons can be variable and thus unpredictable prior to surgery. There are controversies regarding parameters such as gender, height, age, and body mass index to be used pre-operatively to reveal the true graft diameter [5-8]. The most common method of imaging prediction is reported magnetic resonance imagingderived cross-sectional area of both the semitendinosus and gracilis tendons [5, 9-12]. Several methods are used to predict intraoperative bundle diameters during double-bundle ACL reconstruction including MRI cross-sectional area (CSA) of the hamstring tendons and the technique of two perpendicular diameters (in anterolateral and lateral-medial directions) [9-12].

The objective was to explore the influence of anthropometric data and cross-sectional area of semitendinosus (ST) and gracilis (GR) tendons according to preoperative magnetic resonance imaging (MRI) on intraoperative graft diameter.

Ryazantsev M.S., Magnitskaya N.E., Zaripov A.R., Logvinov A.N., Ilyin D.O., Afanasyev A.P., Frolov A.V., Korolev A.V. Anthropometric data and the cross-sectional area (CSA) of the semitendinosus and gracilis tendons measured with preoperative MRI to predict graft diameter for anterior cruciate ligament reconstruction. Genij Ortopedii, 2021, vol. 27, no 2, pp. $237-242$. DOI 10.18019/1028-4427-2021-27-2-237-242 


\section{MATERIAL AND METHODS}

The study included patients who were diagnosed with complete ACL tear and underwent arthroscopic ACL reconstruction at the European Clinic of Sports Traumatology and Orthopaedics (ECSTO) between 2015 and 2018. There were total 215 ACL reconstructions performed during this period. Inclusion criteria were a complete ACLrupture verified by physical examination and MRI scanning and reconstructed at our hospital; use of the quadrupled semitendinosus and gracilis tendon $(\mathrm{St}+\mathrm{Gr})$, available preoperative MRI scan of the knee (magnetic field strength of more than $1.5 \mathrm{~T}$, slice thickness of $3 \mathrm{~mm}$ ) in the records. Exclusion criteria were use of a different graft, different autograft preparation technique, unavailable preoperative MRI scan of the knee in the records, multiligmental injuries of the knee joint. With the inclusion and exclusion criteria applied, the study comprised 111 participants (69 males and 42 females). ACL reconstruction was performed according to the standard procedure described earlier [13]. The intraoperative questionnaire included the length of each tendon separately, the length and diameter (Fig. 1) of the final graft. Height, weight and BMI were recorded in all patients preoperatively.

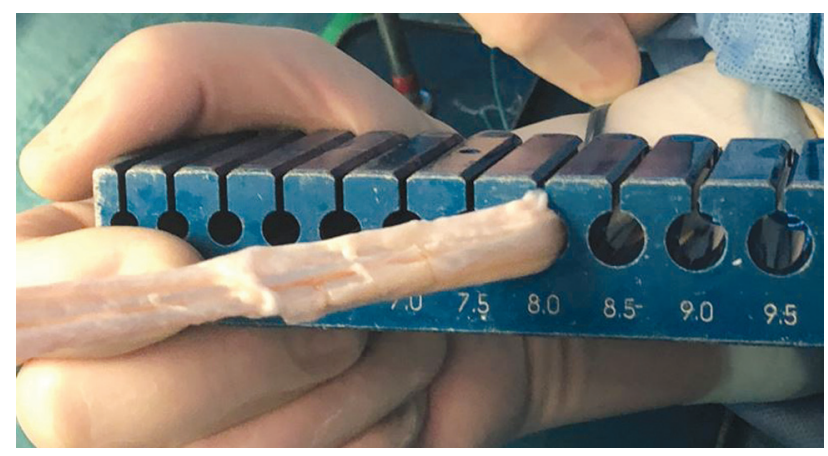

Fig. 1 Intraoperative measurement of the graft diameter

Written informed consent for the participation in the research project was obtained from each subject.
The study received a favourable opinion from the relevant research ethics committee.

\section{MRI diagnosis}

Semitendinosus and gracilis tendon cross sectional areas (CSAst and CSAgr, respectively) were measured on preoperative MRI axial images using 3Di PACSViewer 3.2. Coronary T1 - weighted images were used for identifying the level of the axial section below the closed femoral growth zone. At this level, the course of the tendons is close to vertical to allow a reproducible measurement of the CSA. CSAst and CSAgr were measured in $\mathrm{mm} 2$ on the axial section using the standard "free form" tool (Fig. 2). Then CSAst and CSAgr were combined using the CSAst + CSAgr formula. The measurements were tabulated for further data processing.

CSAst and CSAgr were calculated preoperatively with $4 \times$ magnification, as reported by JI Erquicia et al., for greater accuracy [9].

\section{Statistical analysis}

Statistical analysis was performed using the tools of STATISTICA 12.0, Stat Soft, Inc. An algorithm for calculating linear and logistic regressions was created in the python programming language. The normality of the distribution was determined with the Kolmogorov-Smirnov test. The data obtained were summarized as means \pm standard deviations with maximal and minimal values in normal distribution. Linear regression and the Pearson correlation coefficient were used to measure causal relationships between the graft diameter and the height, weight, BMI, ST and GR length, CSAst, CSAgr, CSAst + CSAgr. Logistic regression was used to determine a probability of obtaining a graft diameter $\geq 7.5$ (the mean autograft diameter in the study) with a change in the CSAst+gr value. For calculations, a significance level of $5 \%(\mathrm{p} \leq 0.05)$ was adopted.
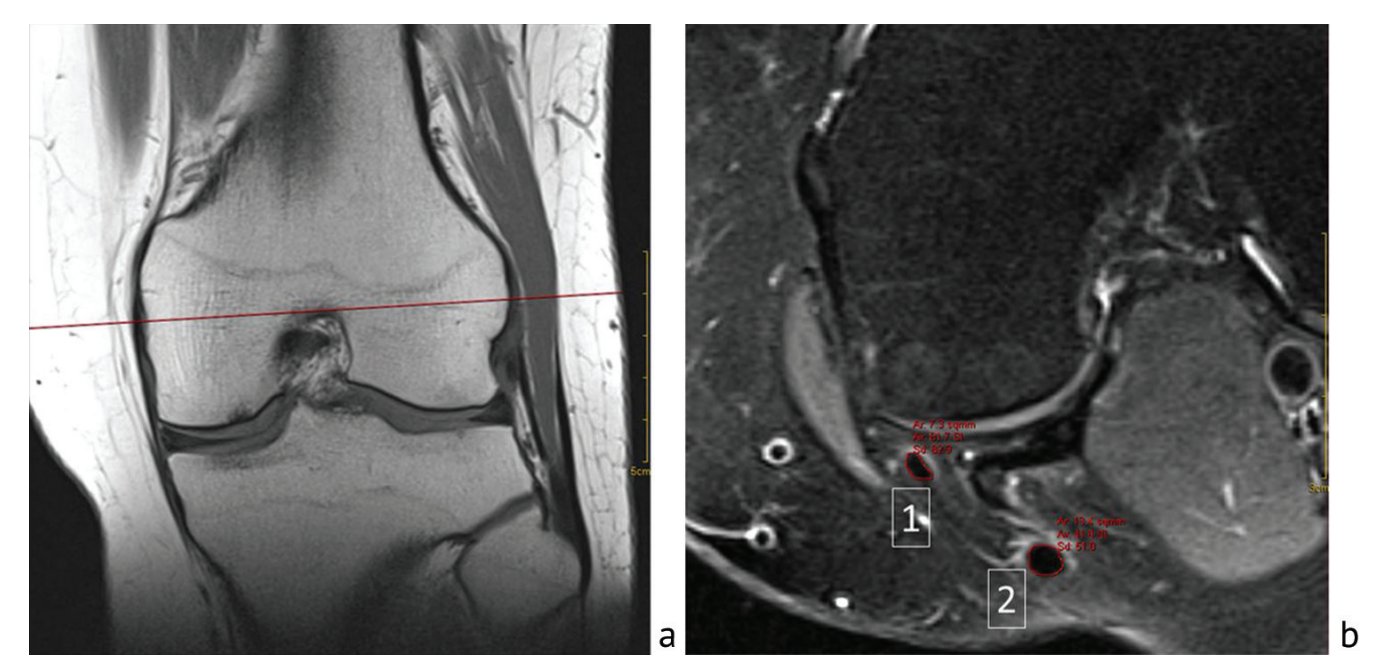

Fig. 2 Semitendinosus and gracilis tendons cross sectional areas (CSAst and CSAgr, respectively) measured on MR images: $\boldsymbol{a}$ identifying the level of the axial section in the coronal plane; $\boldsymbol{b}$ measuring CSA of the tendons with the "free form" tool on the axial section. 1 , gracilis tendon; 2 , semitendinosus tendon 


\section{RESULTS}

There were $62.2 \%(\mathrm{n}=69)$ male and $37.8 \%$ $(n=42)$ female patients. The mean autograft diameter was $7.5 \mathrm{~mm}$ (range, 6.5 to $9.5 \mathrm{~mm}$ ). Demographic and clinical parameters are presented in Table 1. CSAs of the tendons are shown in Table 2. The distribution of graft diameters based on the tendon area measured on MRI scan (CSAst+gr) is shown in Figure 3.

The Pearson correlation coefficient showed greater relationships $(\mathrm{r}<0.5)$ between the combined semitendinosus and gracilis graft diameters (CSAst+gr), semitendinosus graft diameter (CSAst+gr), the height and body weight; moderate correlation $(0.3<\mathrm{r}<0.5)$ between gender and the gracilis graft diameter (CSAgr); weak correlation $(r<0.3)$ between semitendinosus and gracilis tendon length and intraoperative graft diameter (Fig. 4).

Table 1

Demographic and clinical parameters of the study group

\begin{tabular}{|l|c|c|c|c|c|}
\hline \multicolumn{1}{|c|}{ Description } & Quantity & Mean & Standard error & Min & Max \\
\hline Age & 111 & 37.35 & 0.89 & 13 & 58 \\
\hline Height $(\mathrm{cm})$ & 111 & 174.6 & 0.84 & 156 & 200 \\
\hline Weight $(\mathrm{kg})$ & 111 & 78.5 & 1.52 & 45 & 120 \\
\hline BMI & 111 & 25.6 & 0.37 & 18,5 & 41,5 \\
\hline GR length $(\mathrm{mm})$ & 111 & 224.7 & 3.06 & 80 & 340 \\
\hline ST length $(\mathrm{mm})$ & 111 & 256.3 & 2.97 & 160 & 340 \\
\hline Graft length & 111 & 111.3 & 1.42 & 80 & 140 \\
\hline
\end{tabular}

BMI, body mass index; ST - semitendinosus tendon; GR - gracilis tendon; Min, minimal value; Max - maximal value

Table 2

Semitendinosus and gracilis tendons cross sectional areas measured on MR images

\begin{tabular}{|l|c|c|c|c|c|}
\hline \multicolumn{1}{|c|}{ CSA, $\mathrm{mm}^{2}$} & Quantity & Mean & Standard error & Min & Max \\
\hline CSAgr & 111 & 8,95 & 0,21 & 4,30 & 15,90 \\
\hline CSAst & 111 & 14,98 & 0,33 & 7,60 & 25,20 \\
\hline CSAst+gr & 111 & 24 & 0,47 & 13 & 38 \\
\hline
\end{tabular}

CSA, Cross Sectional Area; gr - gracilis tendon; st - semitendinosus tendon

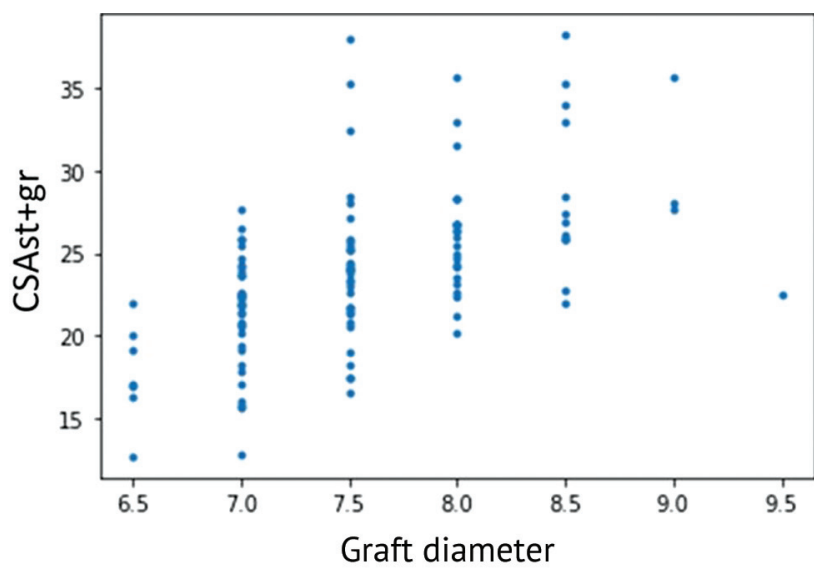

Fig. 3 Distribution of graft diameters based on the tendon area measured on MR images (CSAst+gr)

\begin{tabular}{|c|c|c|c|c|c|c|c|c|c|c|}
\hline & Height & Weight & BMI & Gender & $\begin{array}{l}\text { Semitendinosus } \\
\text { length }\end{array}$ & Gracilis length & CSAgr & CSAst & CSAst+gr & Diameter \\
\hline Height & 1.000000 & 0.711573 & 0.304269 & 0.650327 & 0.412127 & 0.296996 & 0.379824 & 0.414916 & 0.460525 & 0.558120 \\
\hline Weight & 0.711573 & 1.000000 & 0.882051 & 0.571473 & 0.249176 & 0.167484 & 0.403582 & 0.540381 & 0.559198 & 0.520093 \\
\hline BMI & 0.304269 & 882051 & 1.000000 & 0.348099 & 0.067150 & 0.014837 & 0.292277 & 0.455786 & 0.450216 & 033017 \\
\hline & 650327 & 0.571473 & 0.348099 & 1.000000 & 0.163676 & 0.150791 & 0.273575 & 0.357420 & 0.372823 & 0.462464 \\
\hline $\begin{array}{r}\text { Semitendinosus } \\
\text { length }\end{array}$ & 0.412127 & 0.249176 & 0.067150 & 0.163676 & 1.000000 & 0.631847 & 0.055432 & 0.173096 & 0.146225 & 0.183913 \\
\hline Gracilis length & 0.296996 & 0.167484 & 0.014837 & 0.150791 & 0.631847 & 1.000000 & 0.179765 & 0.174416 & 0.202544 & 0.269906 \\
\hline CSAgr & 0.379824 & 0.403582 & 0.292277 & 0.273575 & 0.055432 & 0.179765 & 1.000000 & 0.493280 & 0.791841 & 0.406051 \\
\hline CSAst & 0.414916 & 0.540381 & 0.455786 & 0.357420 & 0.173096 & 0.174416 & 0.493280 & 1.000000 & 0.921853 & 0.537170 \\
\hline CSAst+gr & 0.460525 & 0.559198 & 0.450216 & 0.372823 & 0.146225 & 0.202544 & 0.791841 & 0.921853 & 1.000000 & 0.558043 \\
\hline Diameter & 0.558120 & 0.520093 & 0.336017 & 0.462464 & 0.183913 & 0.269906 & 0.406051 & 0.537170 & 0.558043 & 1.000000 \\
\hline
\end{tabular}

Fig. 4 The Pearson correlation coefficient for the study parameters: BMI, body mass index; gr, gracilis tendon; st, semitendinosus tendon; CSA, Cross Sectional Area; Diameter, intraoperative graft diameter 
A linear regression model was used to determine the effect of the study parameters on the graft diameter. The CSAst+gr parameter was excluded from the first model due to the direct linear relationship with the semitendinosus and gracilis graft diameters (CSAgr, CSAst). The first linear regression model included the following parameters: height, weight, gender, semitendinosus graft diameter (CSAst), gracilis graft diameter (CSAgr) and intraoperative graft diameter. The coefficients measured showed the increase in the resultant value with an increase in a particular input parameter by 1 and the rest being persistent. The coefficients can be used to isolate the effect of a parameter of interest and establish a causal relationship. The first linear regression model showed that gender, weight and CSAgr had no significant effect on graft diameter (model coefficients: 0.11295525, 0.04709301, 0.0966631), while CSAst and height did (0.30405621 and 0.28827937 ). To assess the impact of CSAst+gr, a separate linear regression model was created, with a model coefficient of 0.5580434 , respectively. Thus, the maximum direct effect on the graft diameter was exerted by CSAst+gr, CSAst and height. The CSAgr parameters, weight, gender and semitendinosus and gracilis tendon length had a minimal direct effect tending to zero. A linear classifier model (logistic regression) was used to classify the intraoperative graft diameter $(\geq 7.5 \mathrm{~mm})$. With the maximum impact on the result of the CSAst + gr parameter the classifier was relied on this parameter (Fig. 5).

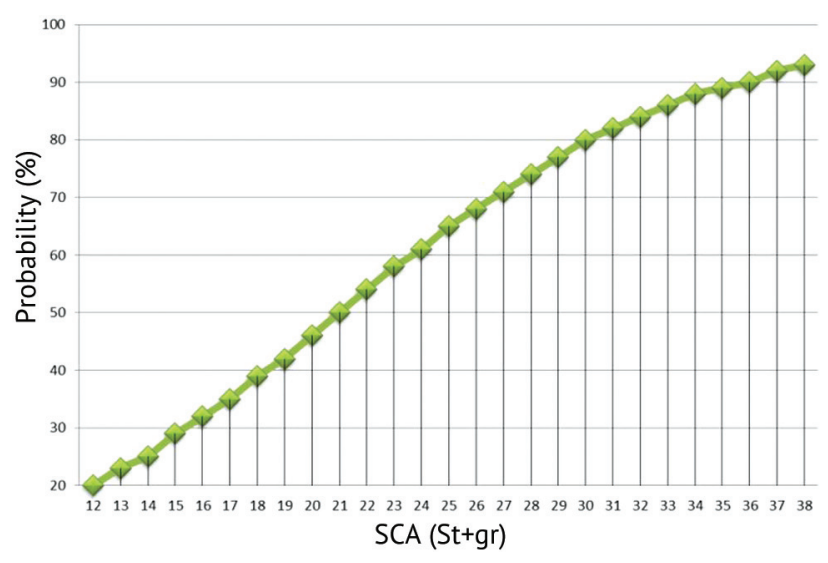

Fig. 5 Probability of obtaining graft diameter of 7.5 $\mathrm{mm}$ and over is related to CSAst+gr value: CSA, Cross Sectional Area; gr, gracilis tendon; st, semitendinosus tendon

Therefore, with the CSAst + gr value $\geq 30 \mathrm{~mm}^{2}$, the likelihood of obtaining an intraoperative graft with a diameter of $7.5 \mathrm{~mm}$ and over was $80.1 \%$.

\section{DISCUSSION}

Quadrupled semitendinosus and gracilis autologous grafts have been used extensively for arthroscopic ACL reconstruction $[2,3,14,15]$. The ability to predict the tendon diameter and, consequently, the graft diameter can help the surgeon in preoperative planning for the optimal choice of an autograft for ACL reconstruction, as well as graft techniques (five-bundle, augmentation, etc.). The autograft diameter is an individual value that cannot be measured prior to harvesting and intraoperative preparation. However, graft diameter is a predictive factor that impacts the strength of fixation and the likelihood of autograft failure $[5,16,17]$. M.A. Magnussen et al. reported decreased hamstring autograft size and decreased patient age $(<20$ years $)$ being predictors of early graft revision [18].

There are controversies regarding preoperative anthropometric parameters being correlated with diameter of quadrupled hamstring graft [6, 19-21]. This can be ascribed to a "gap" in the standardization of MRI protocols (slice thickness, magnetic field strength and number of sequences), the different methods of measuring CSA, the variety of software used to produce the measurements and conditional anatomical landmarks (the level below the closed growth zone). Another possible limitation is an inaccurate measurement of the intraoperative graft diameter using a template with $5 \mathrm{~mm}$ diameter step. Height was reported a statistically significant prediction variable. J.M. Tuman et al. reported hamstring graft diameter being related to height $(r=0.36, p<0.001)$, mass $(r=0.25, p=0.005)$, age $(r=0.16, p=0.05)$ and gender $(r=0.24, p=0.006)$ but was not related to BMI $(p>0.05)$ [20]. S.Y. Park et al. reported intraoperative semitendinosus and fourstrand graft diameters having the strongest associations with height $(\mathrm{r}=0.436, \mathrm{r}=0.477$, respectively) [16]. The series reported by J. Leiter et al. demonstrated height, $(r=0.205)$, weight $(r=0.35)$, BMI $(r=0.262)$ being positively correlated with intraoperative graft diameter [22].

Our series showed height $(\mathrm{r}=0.57)$ and weight $(r=0.52)$ having the strongest correlation with graft diameters. A mean preoperative MRI tendon CSAst of $14.98 \mathrm{~mm}^{2}$ measured in our series is in line with that reported by G. Wernecke measuring $16.5 \mathrm{~mm}^{2}$ [10], B. A. Bickel, $13.3 \mathrm{~mm}^{2}$ [11]. A mean preoperative MRI tendon CSAgr of $8.95 \mathrm{~mm} 2$ is in line with that reported by B.A Bickel measuring $6.97 \mathrm{~mm} 2$ [11]. The strongest indicators of a four-stranded hamstring graft in our series were CSAst+gr and CSAst that is in line with those reported by J. Leiter et al. who detected CSAst+gr as the strongest indicators of the graft diameter [22]. 
J.I. Erquicia et al. reported final graft diameters of $8 \mathrm{~mm}$ in $76.9 \%$ of patients with a CSAst $+\mathrm{gr}>25 \mathrm{~mm}^{2}$ [9]. B.A. Bickel et al. reported an $88 \%$ probability of obtaining a graft of $7 \mathrm{~mm}$, if the combined crosssectional areas CSAst + gr measured $18 \mathrm{~mm} 2$ [11]. Similar measurements were obtained in our series with an $80.1 \%$ probability of obtaining an intraoperative graft with a diameter of $7.5 \mathrm{~mm}$, if the combined crosssectional areas CSAst + gr measured $\geq 30 \mathrm{~mm}^{2}$.
Preoperative planning is an integral part of surgery. Despite the state-of-the-art instrumentation and reproducibility of surgical techniques, the use of autologous tissues for an ACL graft does not allow us to accurately predict the diameter. This study may help in the preoperative planning of surgical treatment of ACL ruptures. The limitations of our study include the small sample size, possible measurement errors on preoperative and intraoperative MR images.

\section{CONCLUSION}

The combined cross-sectional areas of obtaining a quadrupled graft of sufficient size at the time semitendinosus and gracilis tendons measured on MRI of surgery. Our findings show that graft diameter was scans can be used as a predictive characteristic for mainly influenced by CSAst + gr, CSAst and height.

Level of evidence: $I V$

Design: prognostic, cohort study

Conflict of interest: none

Funding: The authors received no financial support for the research and/or authorship of this article.

Acknowledgement: The team of authors expresses their sincere gratitude to Yulia Logvinova for her help in processing and interpreting statistical data.

\section{REFERENCES}

1. Abram S.G., Price A.J., Judge A., Beard D.J. Anterior cruciate ligament (ACL) reconstruction and meniscal repair rates have both increased in the past 20 years in England: hospital statistics from 1997 to 2017. Br. J. Sports Med., 2020, vol. 54, no. 5, pp. 286-291. DOI: 10.1136/bjsports-2018-100195

2. Mall N.A., Chalmers P.N., Moric M., Tanaka M.J., Cole B.J., Bach B.R. Jr., Paletta G.A. Jr. Incidence and trends of anterior cruciate ligament reconstruction in the United States. Am. J. Sports Med., 2014, vol. 42, no. 10, pp. 2363-2370. DOI: 10.1177/0363546514542796

3. Leiter J.R., Gourlay R., McRae S., de Korompay N., MacDonald P.B. Long-term follow-up of ACL reconstruction with hamstring autograft. Knee Surg. Sports Traumatol. Arthrosc., 2014, vol. 22, no. 5, pp. 1061-1069. DOI: 10.1007/s00167-013-2466-3

4. Snaebjörnsson T., Hamrin Senorski E., Ayeni O.R., Alentorn-Geli E., Krupic F., Norberg F., Karlsson J., Samuelsson K. Graft diameter as a predictor for revision anterior cruciate ligament reconstruction and KOOS and EQ-5D values: a cohort study from the Swedish National Knee Ligament Register based on 2240 patients. Am. J. Sports Med., 2017, vol. 45, no. 9, pp. 2092-2097. DOI: 10.1177/0363546517704177

5. Conte E.J., Hyatt A.E., Gatt C.J. Jr., Dhawan A. Hamstring autograft size can be predicted and is a potential risk factor for anterior cruciate ligament reconstruction failure. Arthroscopy, 2014, vol. 30, no. 7, pp. 882-890. DOI: 10.1016/j.arthro.2014.03.028

6. Ma C.B., Keifa E., Dunn W., Fu F.H., Harner C.D. Can pre-operative measures predict quadruple hamstring graft diameter? Knee, 2010, vol. 17, no. 1, pp. 81-83. DOI: 10.1016/j.knee.2009.06.005

7. Pinheiro L.F. Jr., de Andrade M.A., Teixeira L.E., Bicalho L.A., Lemos W.G., Azeredo S.A., da Silva L.A., Gonzaga L.G. Intra-operative fourstranded hamstring tendon graft diameter evaluation. Knee Surg. Sports Traumatol. Arthrosc., 2011, vol. 19, no. 5, pp. 811-815. DOI: 10.1007/ s00167-010-1387-7

8. Xie G., Huangfu X., Zhao J. Prediction of the graft size of 4-stranded semitendinosus tendon and 4-stranded gracilis tendon for anterior cruciate ligament reconstruction: A Chinese Han patient study. Am. J. Sports Med., 2012, vol. 40, no. 5, pp. 1161-1166. DOI: 10.1177/0363546511435627

9. Erquicia J.I., Gelber P.E., Doreste J.L., Pelfort X., Abat F., Monllau J.C. How to improve the prediction of quadrupled semitendinosus and gracilis autograft sizes with magnetic resonance imaging and ultrasonography. Am. J. Sports Med., 2013, vol. 41, no. 8, pp. 1857-1863. DOI: $10.1177 / 0363546513479340$

10. Wernecke G., Harris I.A., Houang M.T., Seeto B.G., Chen D.B., MacDessi S.J. Using magnetic resonance imaging to predict adequate graft diameters for autologous hamstring double-bundle anterior cruciate ligament reconstruction. Arthroscopy, 2011, vol. 27, no. 8, pp. 1055-1059. DOI: 10.1016/j.arthro.2011.02.035

11. Bickel B.A., Fowler T.T., Mowbray J.G., Adler B., Klingele K., Phillips G. Preoperative magnetic resonance imaging cross-sectional area for the measurement of hamstring autograft diameter for reconstruction of the adolescent anterior cruciate ligament. Arthroscopy, 2008, vol. 24, no. 12, pp. 1336-1341. DOI: 10.1016/j.arthro.2008.07.012

12. Beyzadeoglu T., Akgun U., Tasdelen N., Karahan M. Prediction of semitendinosus and gracilis autograft sizes for ACL reconstruction. Knee Surg. Sports Traumatol. Arthrosc., 2012, vol. 20, no. 7, pp. 1293-1297. DOI: 10.1007/s00167-011-1770-Z

13. Korolev A.V., Magnitskaia N.E., Riazantsev M.S., Pilipson Zh.Iu., Khasanshin M.M., Ilin D.O. Vzaimosviaz polozheniia kostnykh kanalov pri artroskopicheskoi plastike perednei krestoobraznoi sviazki, intraoperatsionnykh pozhelanii khirurga i antropometricheskikh dannykh patsienta [The relationship between the position of bone canals during arthroscopic plastics of the anterior cruciate ligament, the surgeon's intraoperative wishes and the patient's anthropometric data]. Travmatologiia i Ortopediia Rossii, 2016, vol. 22, no. 1, pp. 85-95. (in Russian)

14. Slastinin V.V., Fain A.M., Vaza A.Iu. Ispolzovanie transplantata iz sukhozhilii podkolennykh myshts dlia plastiki perednei krestoobraznoi sviazki (preimushchestva, problemy i puti ikh resheniia) [The use of hamstring tendon graft for the anterior cruciate ligament reconstruction (advantages, problems and ways to solve them)]. Transplantologiia, 2017, vol. 9, no. 4, pp. 317-324. (in Russian)

15. Irismetov M.E., Usmonov F.M., Shamshimetov D.F., Kholikov A.M., Razhabov K.N., Tadzhinazarov M.B. Iskhody vosstanovleniia perednei krestoobraznoi sviazki [Outcomes of anterior cruciate ligament reconstruction]. Genij Ortopedii, 2019, vol. 25, no. 3, pp. 285-289. DOI: $10.18019 / 1028-4427-2019-25-3-285-289$

16. Park S.Y., Oh H., Park S., Lee J.H., Lee S.H., Yoon K.H. Factors predicting hamstring tendon autograft diameters and resulting failure rates after anterior cruciate ligament reconstruction. Knee Surg. Sports Traumatol. Arthrosc., 2013, vol. 21, no. 5, pp. 1111-1118. DOI: 10.1007/s00167-012-2085-4

17. Mariscalco M.W., Flanigan D.C., Mitchell J., Pedroza A.D., Jones M.H., Andrish J.T., Parker R.D., Kaeding C.C., Magnussen R.A. The influence of hamstring autograft size on patient-reported outcomes and risk of revision after anterior cruciate ligament reconstruction: a Multicenter Orthopaedic Outcomes Network (MOON) Cohort Study. Arthroscopy, 2013, vol. 29, no. 12, pp. 1948-1953. DOI: 10.1016/j.arthro.2013.08.025

18. Magnussen R.A., Lawrence J.T., West R.L., Toth A.P., Taylor D.C., Garrett W.E. Graft size and patient age are predictors of early revision after anterior cruciate ligament reconstruction with hamstring autograft. Arthroscopy, 2012, vol. 28, no. 4, pp. 526-531. DOI: 10.1016/j.arthro.2011.11.024 
19. Ho Loong S.W., Tan Lester T.J., Lee Thiam K. Role of anthropometric data in the prediction of 4-stranded hamstring graft size in anterior cruciate ligament reconstruction. Acta Orthop. Belg., 2016, vol. 82, no. 1, pp. $72-77$.

20. Tuman J.M., Diduch D.R., Rubino L.J., Baumfeld J.A., Nguyen H.S., Hart J.M. Predictors for hamstring graft diameter in anterior cruciate ligament reconstruction. Am. J. Sports Med., 2007, vol. 35, no. 11, pp. 1945-1949. DOI: 10.1177/0363546507304667

21. Goyal S., Matias N., Pandey V., Acharya K. Are pre-operative anthropometric parameters helpful in predicting length and thickness of quadrupled hamstring graft for ACL reconstruction in adults? A prospective study and literature review. Int. Orthop., 2016, vol. 40, no. 1, pp. 173-181. DOI: $10.1007 / \mathrm{s} 00264-015-2818-3$

22. Leiter J., Elkurbo M., McRae S., Chiu J., Froese W., MacDonald P. Using pre-operative MRI to predict intraoperative hamstring graft size for anterior cruciate ligament reconstruction. Knee Surg. Sports Traumatol. Arthrosc., 2017, vol. 25, no. 1, pp. 229-235. DOI: 10.1007/s00167-016-4205-z

Received: 19.11 .2020

\section{Information about authors:}

1. Michael S. Ryazantsev, M.D., Ph.D., European clinic of sports traumatology and orthopedics (ECSTO), Moscow, Russian Federation, Email: ryaz.doc@yandex.ru

2. Nina E. Magnitskaya, M.D., Ph.D.,

European clinic of sports traumatology and orthopedics (ECSTO), Moscow, Russian Federation

3. Aziz R. Zaripov,

European clinic of sports traumatology and orthopedics (ECSTO), Moscow, Russian Federation, Peoples Friendship University of Russia, Moscow, Russian Federation

4. Aleksei N. Logvinov, M.D.,

European clinic of sports traumatology and orthopedics (ECSTO), Moscow, Russian Federation

5. Dmitriy O. Ilyin, M.D., Ph.D.,

European clinic of sports traumatology and orthopedics (ECSTO), Moscow, Russian Federation

6. Alexei P. Afanasyev, M.D., Ph.D.,

European clinic of sports traumatology and orthopedics (ECSTO), Moscow, Russian Federation

7. Aleksandr V. Frolov, M.D., Ph.D.,

European clinic of sports traumatology and orthopedics (ECSTO), Moscow, Russian Federation,

Peoples' Friendship University of Russia, Moscow, Russian Federation

8. Andrey V. Korolev, M.D., Ph.D., Professor,

European clinic of sports traumatology and orthopedics (ECSTO), Moscow, Russian Federation, Peoples' Friendship University of Russia, Moscow, Russian Federation 